bibuc@ug.edu.pl

Biblioteka Uniwersytetu Gdańskiego

\title{
ANALIZA PRZESTRZENI INFORMACYJNEJ BIBLIOTEKI UNIWERSYTETU GDAŃSKIEGO
}

\begin{abstract}
The modern world is dominated by information, the importance of which is constantly growing. To say that members of the modern society are living in information's environment is truism, but most important thing in the communication process is commitment of technology. This increases the importance of digital competence and increases the aspirations of society in respect of access to knowledge in a fast, easy and convenient way. Contemporary infospace, especially virtual, is more and more complex, dynamic and scattered. An example of such space mighty be online digital libraries, databases, and catalogs. This article discusses how the Library of the University of Gdańsk is now making an attempt to respond to or client's needs.
\end{abstract}

Słowa kluczowe: przestrzeń infor macyjna, Biblioteka Uniwer sytetu Gdańskiego

\section{Przestrzeń informacyjna}

Rozwój technologii oraz sieci komputerowych, zwłaszcza Internetu, spowodowały lawinowy wzrost zdalnie dostępnych informacji cyfrowych. Nadmiar informacji oraz wielość narzędzi informacyjnych, które teoretycznie miały ułatwić proces wyszukiwania informacji $\mathrm{w}$ sieci, w praktyce utrudniają bądź nawet przeszkadzają $\mathrm{w}$ znalezieniu relewantnej informacji ${ }^{1}$. Komunikacja między użytkownikiem a systemami informacyjnymi to obszar nazywaną przestrzenia informacyjną.

Cliff McKnight przestrzeń informacyjną definiuje jako „obiekty (realne lub wirtualne), z których korzysta dana osoba w celu zdobycia informacji”"2. Wedhug Kat Hagedom ,przestrzeń informacyjna jest sumą informacji

\footnotetext{
${ }^{1}$ W. Babik, Ekologia informacji, Kraków 2014, s. 81-83.

${ }^{2} \mathrm{C}$. McKnight, The personal construction of information space, cyt. za: E. Głowacka [et al.], Model indywidualnej przestrzeni informacyjnej w procesie badawczym - wstępne zatożenia, „Zagadnienia Informacji Naukowej. Studium informacyjne” 2015, nr 2 (106), s. 18.
} 
o obszarze zainteresowań"3. Małgorzata Kisilowska termin ten definiuje jako „wielowymiarowy, otwarty zbiór treści (danych i informacji), ich nośników oraz użytkowników”“4. Pojęcie ,,przestrzeni informacyjnej”, które ukształtowało się pod koniec lat dziewięćdziesiątych ubiegłego wieku, bywa używane jako synonim „infosfery” i „środowiska informacyjnego” - określenia o dłuższej historii.

Przestrzeń informacyjna może być fizyczna, mentalna lub wirtualna, może mieć charakter dwuwymiarowym lub trójwymiarowy, globalny lub jednostkowy. Rodzaj, wielkość i sposób zorganizowania przestrzeni mają wpływ na sposób wyszukiwania informacji, potrzebne środki komunikacji, narzędzia czy też czas dotarcia do informacji ${ }^{6}$.

Na przestrzeń informacyjną składają się różnego rodzaju dokumenty, powiązania między nimi, różnego rodzaju struktury - katalogi, sieci. Istotna jest również przestrzeń pojęciowa, wyznaczona zarówno przez treść dokumentów, jak również „struktury poznawcze użytkownika” ${ }^{\text {, }}$, a także zachowania informacyjne użytkowników.

Zdaniem Kisilowskiej na „przestrzeń informacyjną” składają się trzy kategorie elementów:

- $\quad$ treści, w których wyróżnić można dane i informacje;

- nośniki, do którego zalicza „każdy materiał, każde miejsce, na i w jakim mogą być przechowywane treści"

- $\quad$ użytkownicy, którzy są elementem aktywnym tej przestrzeni, „korzystając $\mathrm{z}$ odpowiednich narzędzi i metod, docierają do poszukiwanych informacji bądź eksplorują nowe dla nich źródła"

Zdaniem Katarzyny Materskiej współczesna infoprzestrzeń, w tym przestrzeń informacyjna Internetu, jest skomplikowana, dynamiczna i rozproszona. Wydaje się być nieograniczona, co więcej, ciągle się rozszerza ${ }^{10}$. Przykładem takiej przestrzeni mogą być cyfrowe biblioteki online, bazy danych, katalogi, usługi.

\footnotetext{
${ }^{3}$ K. Hagedorn, The information architecture giossary, cyt. za: M. Kisilowska, Przestrzeń informacyjna jako termin informatologicznym, s. 37, http://bbc.uw.edu.pl/Content/1848/z2011 _2_03.pdf, [dostęp: 17.04.2017].

${ }^{4}$ M. Kisilowska, op. cit., s. 49.

${ }^{5}$ Ibidem, s. 35-49.

${ }^{6} \mathrm{~K}$. Materska, Informacja $w$ organizacjach spoleczeństwa wiedzy, Warszawa 2007, s. $199-200$.

${ }^{7}$ Ibidem, s. 200.

${ }^{8}$ M. Kisilowska, op. cit., s. 50.

${ }^{9}$ Ibidem, s. 50.

${ }^{10}$ Ibidem, s. 200.
} 


\section{Przestrzeń informacyjna Biblioteki Uniwersytetu Gdańskiego}

Zdaniem Jacka Wojciewskiego podstawową funkcją biblioteki jest „mediacja, czyli pośrednictwo pomiędzy ofertą komunikacyjną a społeczeństwem" ". Aby zaspokoić potrzeby informacyjne użytkowników, biblioteki akademickie muszą posiadać dobrze zbudowaną przestrzeń informacyjną. Ekspansywny rozwój technologii informacyjno-komunikacyjnych wpływa na zmianę oferty usługowo-informacyjnej bibliotek oraz warsztat pracy bibliotekarzy.

Biblioteka Uniwersytetu Gdańskiego (BUG), jak większość bibliotek akademickich, przyjęła postać biblioteki hybrydowej, gdzie obok fizycznej przestrzeni informacyjnej, funkcjonuje przestrzeń wirtualna. W artykule omówione zostaną główne składowe przestrzeni fizycznej i wirtualnej BUG.

Na fizyczną przestrzeń informacyjną BUG składają się: Biblioteka Główna (BG) i siedem bibliotek specjalistycznych: Biblioteka Ekonomiczna (BE), Biblioteka Humanistyczna, Biblioteka Matematyczno-Fizyczna - Czytelnia, Biblioteka Neofilologiczna, Biblioteka Prawna, Biblioteka Historii Kultury i Czytelnia Oceanograficzna. Zbiory bibliotek specjalistycznych obejmują księgozbiór dopasowany do dydaktycznych potrzeb wydziałów Uniwersytetu Gdańskiego (UG), przy których biblioteki funkcjonują.

W BUG użytkownicy mają do dyspozycji 2 wypożyczalnie i 6 czytelni, w których znajduje się 560 miejsc pracy i 83 stanowiska komputerowe. W bibliotekach specjalistycznych znajduje się 47 stanowisk komputerowych, rozmieszczonych w 11 czytelniach. Coraz częściej czytelnicy korzystają z własnych komputerów przenośnych, łącząc się Internetem poprzez osobiste konta w systemie Eduroam. BG dysponuje 28 pokojami pracy indywidualnej, które cieszą się dużym zainteresowaniem oraz 4 pokoje pracy grupowej. Dodatkowo 2 pokoje pracy grupowej mieszczą się w $\mathrm{BE}$.

W systemie biblioteczno-informacyjnym UG najczęściej odwiedzaną placówką jest Biblioteka Główna. W 2016 r. we wszystkich placówkach BUG udostępniono 963813 wol. zbiorów drukowanych, co stanowi spadek o 30023 wol. w stosunku do roku poprzedniego. We wszystkich placówkach BUG w 2016 r. udzielono 127795 informacji ( w tym: 56442 - informacje katalogowe, 8884 - informacje bibliograficzne) oraz zrealizowano 354 kwerendy $^{12}$.

\footnotetext{
${ }^{11}$ J. Wojciechowski, Biblioteczna wartość naddana, Kraków 2006, s. 35.

${ }^{12}$ Sprawozdanie roczne 2016, Gdańsk 2017, s. 19, http://www.bg.ug.edu.pl/images/stories/ pdf/spraw2016.pdf, [dostęp: 10.04.2017].
} 
Drukowane zasoby BUG uzupełnione są o kolekcje elektroniczne. Zasoby elektroniczne, które oparte są na nowoczesnych technologiach informacyjnych, znacznie przyspieszają obieg informacji w świecie nauki, dzięki łatwemu dostępowi do pełnych tekstów z każdego miejsca podłączonego do sieci ${ }^{13}$. BUG dostarcza użytkownikom dostęp do licznych licencjonowanych serwisów elektronicznych: czasopism (Elsevier, Springer, Wiley-Blackwell, a także: American Chemical Society, American Institute of Physics, American Physical Society, Emerald Group Publishing, IOP Publishing, Royal Society of Chemistry) oraz książek (EBSCO, IBUK Libra oraz Academic Research eBooks Library, Encyclopedia Britannica Academic Edition, Gale Virtual Reference Library, Oxford Dictionaries).

Zasoby elektroniczne dostępne są w sieci uniwersyteckiej lub z komputerów domowych poprzez usługę VPN (zdalny dostęp do prenumerowanych baz danych $)^{14}$. Księgozbiór BUG-u liczy około 3190000 tytułów e-książek. Liczba prenumerowanych czasopism elektronicznych wynosi 62585 (pełnotekstowe: 28 936, abstraktów 33 649) ${ }^{15}$. W 2016 r. z usługi VPN skorzystało 2571 użytkowników, którzy wygenerowali 68168 poprawnych sesji. To o 2075 więcej w porównaniu z rokiem poprzednim ${ }^{16}$.

Przyjaznym użytkownikowi narzędziem wyszukiwawczym jest zintegrowane przeszukiwanie e-zasobów - multiwyszukiwarka EBSCO Discovery Service. Jest to narzędzie umożliwiające szybkie przeszukiwanie zawartości baz danych oferowanych przez BUG, bez konieczności przeszukiwania każdej $\mathrm{z}$ baz osobno.

BUG oferuje również dostęp do baz dostępnych dzięki licencji narodowej - w ramach Wirtualnej Biblioteki Nauki. „Wirtualna Biblioteka Nauki (WBN), www.wbn.edu.pl, jest narzędziem badawczym, które umożliwia wszystkim polskim naukowcom bezpłatny dostęp do światowych zasobów wiedzy - elektronicznych baz danych oraz czasopism i publikacji naukowych w wersji elektronicznej”" ${ }^{\prime 1}$. W ramach licencji krajowej WBN ,polski badacz" ma dostęp do: bazy EBSCO, pełnotekstowych baz czasopism takich wydawców, jak: Science Direct (Elsevier), Springer Link, Wiley, czasopism: Nature, Science czy baz cytowań: Web of Knowledge i SCOPUS.

${ }^{13}$ B. Kamińska-Czubała, D. Witczak, Cyfrowe biblioteki Krakowa i Lwowa, [w:] Kraków - Lwów. Książki - czasopisma - biblioteki XIX i XX wieku, t. IX, część 1, red. H. Kosętka, B. Góra, E. Wójcik, Kraków 2009, s. 313.

${ }^{14}$ E-zasoby, Biblioteka Uniwersytetu Gdańskiego, http://www.bg.ug.edu.pl/e-zasoby, [dostęp: 10.04.2017].

${ }^{15}$ Sprawozdanie roczne $2016 \ldots$, s. 20.

${ }^{16}$ Ibidem, s. 10.

${ }^{17}$ Wirtualna Biblioteka Nauki, MNiSW, http://www.nauka.gov.pl/projekty-i-inicjatywy/ wirtualna-biblioteka-nauki.html, [dostęp: 23.08.2017]. 
Uzupełnienie baz komercyjnych oferowanych przez BUG, mogą stanowić zasoby bibliotek cyfrowych, które są darmowe i w większości dostępne dla wszystkich użytkowników Internetu. Wśród polskich bibliotek cyfrowych, dostarczanych przez BUG należy wymienić:

- $\quad$ Pomorską Bibliotekę Cyfrową (PBC);

- Cyfrową Bibliotekę Narodową Polona, która udostępnia najważniejsze wydania tekstów literackich i naukowych, dokumentów historycznych, czasopisma, grafikę, fotografię, nuty oraz mapy stanowiących dziedzictwo kulturalne Polski i będące częścią zbiorów Biblioteki Narodowej;

- $\quad$ serwis umożliwiający przeszukiwanie zasobów polskich bibliotek cyfrowych zrzeszonych w Federacji Bibliotek Cyfrowych $(\mathrm{FBC})^{18}$.

Natomiast bazę bibliotek cyfrowych na świecie oferowanych przez BUG stanowią:

- $\quad$ Europeana - Wirtualna Biblioteka Europejska prezentująca cyfrowe zasoby bibliotek oraz instytucji naukowych i kulturalnych krajów Unii Europejskiej, za pośrednictwem której można również przeglądać zbiory polskich bibliotek cyfrowych;

- $\quad \mathrm{ViFaOst} \mathrm{-} \mathrm{Wirtualna} \mathrm{Biblioteka} \mathrm{Europy} \mathrm{Wschodniej} \mathrm{umożliwiająca} \mathrm{wy-}$ szukiwanie specjalistycznych informacji naukowych z zakresu historii, języka, literatury, polityki i kultury wschodnich, środkowo i południowowschodnich krajów europejskich;

- $\quad$ DART Europe - zawiera pełne teksty prac doktorskich i habilitacyjnych powstających w Europie;

- Discover Yale Digital Commons - zawiera kolekcję ponad 25000 zdjęć eksponatów pochodzących z archiwów, muzeów i bibliotek Uniwersytetu Yale $^{19}$.

W tworzeniu Pomorskiej Biblioteki Cyfrowej (PBC) BUG uczestniczy od 2009 r. Jest to najważniejsze wspólne przedsięwzięcie bibliotek naukowych z Trójmiasta i Pomorza. W 2016 r., w grupie bibliotek tworzących zasób PBC, BUG była na pierwszym miejscu pod względem liczby opublikowanych dokumentów. Łączna liczba odwiedzin portalu PBC od 1 grudnia 2009 r. wyniosła 8605 263. W ciągu 2016 r. portal PBC odwiedzily 2246122 osoby, o 605434 więcej w stosunku do 2015 r., a kolekcję przygotowaną przez BUG czytało 383319 osób, o 36756 w stosunku do roku poprzedniego. Największym zainteresowaniem cieszyły się czasopisma, gazety i dokumenty dotyczące historii Trójmiasta i regionu oraz materiały dydaktyczne ${ }^{20}$.

${ }^{18}$ Biblioteki Cyfrowe, Biblioteka Uniwersytetu Gdańskiego, http://www.bg.ug.edu.pl/e-zaso by/biblioteki-cyfrowe, [dostęp: 20.08.2017].

${ }^{19}$ Ibidem.

${ }^{20}$ Sprawozdanie roczne $2016 \ldots$, s. 20. 
Cennym źródłem informacji o dorobku naukowym pracowników akademickich są uczelniane bibliograficzne bazy danych. BG UG opracowuje i udostępnia bazę Bibliografii Publikacji Pracowników, Doktorantów i Studentów UG. W 2016 r. do bazy wprowadzono 9950 rekordów, zaś cała baza liczy 42489 rekordów. Od 2015 r. dane z bazy bibliograficznej UG przesyłane są do Modułu Sprawozdawczego Polskiej Bibliografii Naukowej, będącej częścią systemu informacji o nauce POL-on. Rejestracja danych bibliograficznych odbywa się w systemie Expertus firmy Splendor, który niedługo zostanie zastąpiony systemem OMEGA-PSIR. Jest to program opracowany przez zespół Politechniki Warszawskiej w ramach projektu SYNAT, który pozwoli na tworzenie bazy wiedzy uczelni. ,System gromadzi, archiwizuje i zapewnia łatwy dostęp do wyników prac naukowych, publikacji, informacji o kierunkach i wynikach prowadzonych na Uczelni badań, specjalizacji poszczególnych jednostek organizacyjnych oraz pracowników naukowych"21. Zakres gromadzonych danych dostosowany jest do wymogów MNiSW systemu POL-on. Integralną częścią systemu jest repozytorium, umożliwiające przechowywanie oraz udostępnianie pełnych tekstów publikacji, prac dyplomowych oraz innych dokumentów ${ }^{22}$.

Istotną rolę $\mathrm{w}$ zaspokajaniu potrzeb informacyjnych czytelników BUG odgrywa wypożyczalnia międzybiblioteczna, która w 2016 r. sprowadziła z innych bibliotek 756 wol. (w tym 72 wol. z zagranicy), a wysłała 847 wol. (w tym 35 wol. za granicę). Współpracowano z 288 bibliotekami (w tym z 44 zagranicznymi $)^{23}$.

Ważnym elementem przestrzeni informacyjnej bibliotek jest katalog biblioteczny, obecnie najczęściej występujący już tylko w postaci elektronicznej. Katalog porządkuje świat informacji, w którym „zmuszeni jesteśmy się poruszać, 24 . Publiczne udostępnianie katalogów w środowisku sieciowym, umożliwia przeglądanie ich $\mathrm{z}$ dowolnego komputera, w dowolnym czasie, co zapewnia „czytelnikom dostęp do informacji wiarygodnej, wartościowej, spełniającej kryteria naukowości”25.

${ }^{21}$ O Bazie Wiedzy, Baza Wiedzy Politechniki Warszawskiej, http://repo.bg.pw.edu.pl/index. php/p1/2016-07-05-19-37-36/o-bazie-wiedzy, [dostęp: 10.08.2017].

${ }^{22}$ Sprawozdanie roczne $2016 \ldots$, s. 13.

${ }^{23}$ Ibidem, s. 6.

${ }^{24}$ M. Kisilowska, J. Woźniak-Kasperek, Czy katalog ma przyszłość? Dwugłos względnie uporzadkowany, s. 71, http://www.ebib.pl/publikacje/matkonf/biblio21/sesja2ref3.pdf, [dostęp: 17.04.2017].

${ }^{25}$ Ibidem. 
Katalog BUG od 1 września 2014 r. ma nowy interfejs użytkownika - Chamo - progresywny system, który z założenia ma być przyjazny użytkownikowi. Jest to produkt wzorowany na wyszukiwarce Google, posiada możliwość wyszukiwania przez jedno okno wyszukiwawcze, w które należy wpisać dowolne słowo z opisu publikacji. Dodatkowo istnieje też możliwość wyszukiwania zaawansowanego i przez hasła przedmiotowe. Do zawężenia otrzymywanych $\mathrm{w}$ wyszukiwaniu podstawowym wyników służy system faset (język, miejsce i rok wydania, typ dokumentu, temat). Można też użyć dowolnego hasła, które powinno występować w wyszukiwanych opisach publikacji. Ponadto przy korzystaniu z wyszukiwania zaawansowanego dostępne są szczegółowe filtry, a otrzymane wyniki w wyszukiwaniu podstawowym i zaawansowanym można szeregować według dodatkowych kryteriów (autor, tytuł, data wydania, data dodania opisu do bazy ${ }^{26}$. W 2016 r. odnotowano 388346 wejść na stronę katalogu online $\mathrm{BUG}^{27}$.

Ze względu na złożoność tematu, w artykule omówiono jedynie najistotniejsze aspekty przestrzeni informacyjnej BUG.

\section{Zakończenie}

Wraz z rozwojem technologii przestrzeń informacyjna bibliotek będzie rozbudowywać się o nowe kanały komunikacji, różnego rodzaju nowe struktury, a warto zauważyć, że obecna jest już skomplikowana i dynamiczna. Stopniowo spada wykorzystywalność tradycyjnych źródeł informacji na korzyść elektronicznych. Jednak wirtualna infosfera wydaje się być nieograniczona, co utrudniać użytkownikom poruszanie się w niej. Przy wyszukiwaniu informacji z cyfrowych bibliotek online, baz danych, katalogów pomocny może okazać się bibliotekarz, który przekaże użytkownikowi wiedzę z zakresu, jak pozyskiwać, oceniać i efektywnie wyszukiwać informację.

\section{Bibliografia}

Babik W., Ekologia informacji, Kraków 2014.

E-zasoby, Biblioteka Uniwersytetu Gdańskiego, http://www.bg.ug.edu.pl/e-zasoby, [dostęp: 10.04.2017].

\footnotetext{
${ }^{26}$ U. Kulczycka, B. Roszkowska-Paszuk, Katalog online biblioteki narzędziem komunikacji z czytelnikiem. Analiza funkcjonalności katalogu online Biblioteki UG w oparciu o przeprowadzone badania, [w:] Zarządzanie jakościa w bibliotece: praca zbiorowa, red. M. Wojciechowska, Warszawa 2017, s. 347-356.

${ }^{27}$ Sprawozdanie roczne $2016 \ldots$, s. 7.
} 
Hagedorn K., The information architecture giossary, cyt. za: M. Kisilowska, Przestrzeń informacyjna jako termin informatologicznym, s. 37, http://bbc.uw.edu.pl/ Content/1848/z2011_2_03.pdf, [dostęp: 17.04.2017].

Kamińska-Czubała B., Witczak D., Cyfrowe biblioteki Krakowa i Lwowa, [w:] Kraków - Lwów. Książki - czasopisma - biblioteki XIX i XX wieku, t. IX, część 1, red. H. Kosętka, B. Góra, E. Wójcik, Kraków 2009, s. 313.

Kisilowska M., Przestrzeń informacyjna jako termin informatologicznym, http:// bbc.uw.edu.pl/Content/1848/z2011_2_03.pdf, [dostęp: 17.04.2017].

Kisilowska M., Woźniak-Kasperek J., Czy katalog ma przyszłość? Dwugłos względnie uporzadkowany, http://www.ebib.pl/publikacje/matkonf/biblio21/sesja2ref3. pdf, [dostęp: 17.04.2017].

Kulczycka U., Roszkowska-Paszuk B., Katalog online biblioteki narzędziem komunikacji z czytelnikiem. Analiza funkcjonalności katalogu online Biblioteki UG w oparciu o przeprowadzone badania, [w:] Zarzadzanie jakościa w bibliotece: praca zbiorowa, red. M. Wojciechowska, Warszawa 2017.

Materska K., Informacja w organizacjach społeczeństwa wiedzy, Warszawa 2007.

McKnight C., The personal construction of information space, cyt. za: E. Głowacka [et al.], Model indywidualnej przestrzeni informacyjnej $w$ procesie badawczym - wstępne założenia, „Zagadnienia Informacji Naukowej. Studium informacyjne” 2015, nr 2 (106), s. 18.

O Bazie Wiedzy, Baza Wiedzy Politechniki Warszawskiej, http://repo.bg.pw.edu.pl/ index.php/pl/2016-07-05-19-37-36/o-bazie-wiedzy, [dostęp: 10.08.2017].

Sprawozdanie roczne 2016, Gdańsk 2017, http://www.bg.ug.edu.pl/images/stories/pdf/ spraw2016.pdf, [dostęp: 10.04.2017].

Wojciechowski J., Biblioteczna wartość naddana, Kraków 2006.

Wirtualna Biblioteka Nauki, MNiSW, http://www.nauka.gov.pl/projekty-i-inicjatywy/ wirtualna-biblioteka-nauki.html, [dostęp: 23.08.2017].

Biblioteki Cyfrowe, Biblioteka Uniwersytetu Gdańskiego, http://www.bg.ug.edu.pl/ezasoby/biblioteki-cyfrowe, [dostęp: 20.08.2017]. 